\title{
Correspondence
}

\section{APT for non-consultant career grade doctors?}

On reading Slinn's (2000) recent editorial, I was disappointed that he did not mention non-consultant career grade (NCCG) doctors. I appreciate that the article was aimed at highlighting the strengths of Advances in Psychiatric Treatment (APT) for trainees, but I think it is important that $A P T$ be considered a useful journal for NCCG doctors as well. As a group they are playing an increasingly important role in psychiatric services and should be encouraged to undertake continuing professional development (CPD). APT is one of the better journals in this area. In a recent survey of local psychiatric NCCG doctors, over $85 \%$ of those not currently subscribing to $A P T$ would like to receive it as part of their CPD package. Overall they felt that APT provides better value for money than the current Royal College of Psychiatrists CPD package. Dr Slinn wrote that the process of learning does not change on moving from a training grade to a consultancy, and I believe this also applies to doctors moving into NCCG posts.

I do not take issue with anything that Dr Slinn wrote, but would strongly advocate the use of APT in providing ongoing education for all groups of doctors, especially NCCG doctors.
Slinn, R. (2000) Advances in Psychiatric Treatment for trainees? Advances in Psychiatric Treatment, 6, 241-242.

Dr Simon Budd High Royds Hospital, Menston, Ilkley, West Yorkshire LS29 6AQ

Editor's reply: I would like to thank Dr Budd for his letter: the point is well taken. I am very glad to read that non-consultant career grade (NCCG) doctors enjoy reading Advances in Psychiatric Treatment and find it useful for their continuing professional development (CPD).

Of course we want to target NCCG doctors, as $A P T$ is aimed at providing CPD for all trained psychiatrists, whatever their grade. The purpose of the editorial was to emphasise that $A P T$ is also a useful source for those still in training, both before and after the membership examination. We welcome Dr Budd's response, and we would happily consider any suggestions of ways in which APT could be modified to be more useful to NCCG doctors.

Professor Andrew Sims The Royal College of Psychiatrists, 17 Belgrave Square, London SW1X 8PG 


\section{NEW FROM GASKELL}

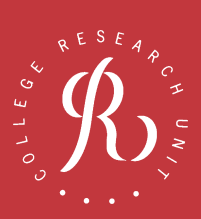

\section{The Mental Health Needs of Looked After Children}

\section{Joanna Richardson \& Carol Joughin}

Young people in the care system have a much higher rate of mental health problems than those in the general population. Failure to acknowledge and treat these problems may cause difficulties for these children ranging from placement breakdowns to more serious mental health problems in later life. This book is valuable to anyone who has contact with young people in care in particular social workers and foster carers.

Developed with a number of professionals, the book aims to help those caring for and working with these vulnerable young people to:

- identify and understand the mental health problems and social issues that may exist for these children;

- be made aware of the importance of recognising mental health problems and therefore the importance of prevention;

- improve understanding of current developments in child and adolescent mental health services, specifically joint working between health and social services.

\section{August 2000, paperback, £14.00, ISBN 190124248 X}

\section{Finding the Evidence: A Gateway to the Literature in Child and Adolescent Mental Health}

Carol Joughin \& Mike Shaw

This resource provides clinicians and trainees with easy access to research evidence and current thinking in child and adolescent mental health. 'Experts' from each area have assisted in compiling this resource, which will be updated on an annual basis. The authors have searched for robust secondary research, key reports and clinical practice guidelines on a wide range of topic areas as well as including cutting edge and classic papers, reviews and books. A section that addresses various approaches to searching for information, search strategies and critical appraisal tools is also included.

We envisage Finding the Evidence: A Gateway to the Literature in Child and Adolescent Mental Health as a 'living document' evolving to address the growing demand for knowledge and plan to exploit the new opportunities provided by information technology.

July 2000, paperback, £12.00, ISBN 1901242501

Book Sales, The Royal College of Psychiatrists, 17 Belgrave Square, London SW1X 8PG. Telephone +44 (0)20 72352351 ext. 146; Fax +44 (0)20 72451231 . 


\section{New Council Reports}

\section{CR77 Services for Younger People with Alzheimer's Disease and other Dementias}

Young sufferers of dementia often fall through the net. This paper is welcomed within the College and strongly supported by the Alzheimer's Society. An incremental approach is advocated with the appointment of two key players; at the commissioning level (health authority/primary groups or their equivalent) a named person responsible for planning and a clinician to act as a focus for referrals, initially two consultant sessions. An Old Age Psychiatrist is well placed to undertake the clinical role. After these appointments have been made the rudiments of the local service are created. At all stages coordination and networking with people already involved with young sufferers is important while the composition and evolution of the new service will depend on existing local services and facilities.

May 2000, 20pp, £5.00

\section{CR78 Safety for Trainees in Psychiatry}

Safety is of paramount importance to all psychiatrists. Just one piece of advice may make all the difference to you or to one of your trainees. This Council Report contains practical advice on maintaining personal safety and sets standards for safety training, interview rooms and on-call accommodation. Recommendations are made about safety training for use on trainees' induction days and for the development of local policies and procedures on safety. Guidance is given about what to do in the event of an assault. This document is essential reading for all educational supervisors, scheme organisers, trainees and anyone interested in personal safety in the field of psychiatry.

August 2000, 20pp, $£ 5.00$

\section{CR79 Guidance for the Use of Video Recording in Child Psychiatric Practice}

Videotape recording of interviews with patients and their families is now commonly used in child psychiatric practice. Involvement in videotape recording has a unique meaning for each patient and their family, and may potentially have a profound effect.There are several purposes for the making of videotape recordings. The recording is based on a prior negotiation with the patient or a responsible adult, including verbal or written explanation and the gaining of formal consent.

This document outlines the procedures involved in videotaping including ensuring confidentiality and obtaining consent. It provides guidance for all child and adolescent psychiatrists who are involved in the making and subsequent use of videotape recording.

August 2000, 16pp, $£ 5.00$

\section{CR80 Good Medical Practice in the Psychiatric Care of Potentially Violent Patients in the Community}

This new Council Report updates and replaces CR12, 'Good Medical Practice in the the aftercare of potentially violent or vulnerable patients discharged from in-patient psychiatric treatment', published in 1991. The scope of this new report is somewhat broader than the 1991 document, as it was considered to be important to recognise that the care necessary for such patients is not only applicable following discharge from hospital. The report outlines current statute and common law, and incorporates guidance from the Department of Health, and The General Medical Council, as well as other pertinent documents, including inquiry reports.

August 2000, 16pp, $£ 5.00$

Book Sales, The Royal College of Psychiatrists, 17 Belgrave Square, London SW1X 8PG. Telephone +44 (0)20 72352351 ext. 146; Fax +44 (0)20 72451231 . 